\title{
Preoperative and intraoperative factors affecting mortality in patients operated on for peptic ulcer perforation: a single center retrospective study
}

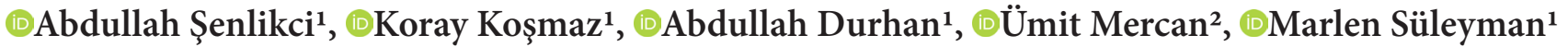 \\ ${ }^{1}$ University of Health Sciences, Ankara Training and Research Hospital, Department of General Surgery, Ankara' Turkey \\ ${ }^{2}$ Ankara University, Faculty of Medicine, Department of Surgical Oncology, Ankara, Turkey
}

Cite this article as: Şenlikci A, Koşmaz K, Durhan A, Mercan Ü, Süleyman M. Preoperative and intraoperative factors affecting mortality in patients operated on for peptic ulcer perforation: a single center retrospective study. J Health Sci Med 2021; 4(3): 344-348.

\begin{abstract}
Aim: Peptic ulcer perforation (PUP) is currently the most common complication of peptic ulcer disease (PUD), which requires surgery. Mortality and morbidity rates are high after surgical treatment. The aim of this study was to determine the predictive factors affecting postoperative mortality in patients undergoing surgery due to peptic ulcer perforation.

Material and Method: The study included 135 patients diagnosed and operated on because of PUP in the general surgery clinic between February 2015 and January 2020. Evaluations were made of the relationships between mortality and age, gender, ASA scores, season of surgery, preoperative leukocyte, preoperative neutrophil to lymphocyte ratio (NLR), preoperative creatinine and amylase values, location and diameter of the perforation, comorbid diseases, onset of pain and time of surgery.

Results: Advanced age, male gender, high ASA score, $>12$ hours between the onset of the symptoms and the time of surgery, and high creatinine, NLR and amylase values before surgery, ulcer diameter $>1 \mathrm{~cm}$ and comorbid diseases were associated with mortality. No relationship was found between the location of the ulcer and leukocyte values at the time of admission and mortality.

Conclusion: Advanced age, male gender, high ASA score, $>12$ hours between the onset of symptoms and the time of surgery, and high preoperative creatinine, NLR and amylase values, ulcer diameter $>1 \mathrm{~cm}$ and comorbid diseases are risk factors for mortality in peptic ulcer perforation. Understanding these factors, identifying patients at risk, and early intervention can help reduce mortality in PUP.
\end{abstract}

Keywords: Peptic ulcer perforation, mortality, peptic ulcer disease

\section{INTRODUCTION}

Peptic ulcer disease (PUD) is one of the most common diseases of the gastrointestinal tract and approximately 4 million people per year are affected worldwide (1). Although the multi-factor etiology of PUD is understood in many ways, life-threatening complications such as bleeding or perforation are seen in a significant number of patients (2). Peptic ulcer perforation (PUP) is one of the causes of high-risk acute abdomen, which accounts for $5 \%$ of all abdominal emergency surgical situations (3). The current most preferred surgical method is simple closure and repair with an omental patch. Despite better understanding of the disease, effective resuscitation and rapid surgery under modern anesthesia techniques, the postoperative morbidity (20-
$50 \%)$ and mortality (3-40\%) rates remain high $(4,5)$. In the past few decades, several risk factors associated with postoperative mortality and morbidity in peptic ulcer perforation have been evaluated. Advanced age, surgery delayed for more than 24 hours, systolic blood pressure $<100 \mathrm{mmHg}$, shock and concomitant diseases have been reported to be the main risk factors affecting mortality (6). Complications after surgical closure of PUP include surgical site infection, pneumonia, intraabdominal abscess, wound separation, enterocutaneous fistula, peritonitis, incision hernia and ileus (7). The American Anesthesiologists Association (ASA) score and Boey score are the most commonly used prognostic scoring systems in patients with PUP (8). 
The aim of this study was to evaluate the relationship between preoperative, intraoperative factors and postoperative mortality and the value of creatinine, amylase and the neutrophil lymphocyte ratio in predicting mortality in patients undergoing surgery due to peptic ulcer perforation in a tertiary center.

\section{MATERIAL AND METHOD}

Prior to implementation, this study's protocol was approved by Ankara Training and Research Hospital Ethics Committee (Date: 01/10/2020, Decision No: 442). This study was carried out in accordance with the principles of the Declaration of Helsinki.

The data were obtained retrospectively from patient files and computer records. The study included 135 patients who were operated on due to peptic ulcer perforation between February 2015 and January 2020. Iatrogenic perforations, non-operative cases and cases with perforation due to malignant ulcer were excluded from the study. In all cases, the diagnosis was made by physical examination and free air observation on abdominal radiograph or abdominal tomography. Graham rafi and omentoplasty were performed on the patients with PUP who were included in the study. The cases were analyzed in two groups as survival and non-survival. The relationships were evaluated between mortality and age, gender, ASA scores, season of surgery, preoperative leukocyte, preoperative neutrophil to lymphocyte ratio (NLR), preoperative creatinine and amylase values, location and diameter of the perforation, comorbid diseases, onset of pain and time to surgery. Then, the value of creatinine, amylase and neutrophil lymphocyte ratio in predicting mortality was evaluated.

\section{Statistical Analysis}

All statistical analysis were performed using IBM Statistics version 23.0 software. All numerical variables were stated as mean \pm standard deviation or percentile values. The conformity of numerical variables to normal distribution was analyzed using histogram graphics and the Kolmogrov-Smirnov test. In the comparisons of demographic, clinicopatholgical and perioperative findings between the groups, the Chi-square test or Fisher Exact test were used for categorical variables and the Student's t-test or Mann-Whitney U-test were used for numerical variables. Binary Logistic Regression analysis was applied to determine the risk factors affecting mortality. A value of $\mathrm{p}<0.05$ was considered statistically significant.

\section{RESULTS}

The comparisons of demographic, clinicopathological, and preoperative findings between the groups of survivors and non-survivors are summarized in Table 1. The mean age was $49.41 \pm 19.09$ and $107(79.3 \%)$ patients were male. Of the 135 patients, $11(8.1 \%)$ developed mortality in the postoperative period and female patients had a significantly higher mortality rate. The majority of patients were in the ASA I group and the ASA score was found to be significantly higher in the non-survivors group compared to the survivors $(\mathrm{p}=0.001)$. Cardiovascular diseases, pulmonary diseases and diabetes mellitus were found to be significantly more frequent in the the group of non-survivors $(\mathrm{p}$ $<0.001 ; \mathrm{p}<0.001 ; \mathrm{p}<0.001$ respectively).

When the operation dates were examined, it was observed that the patients were operated on most frequently in June (13.3\%) and other summer months, and the mortality rate was significantly higher in the winter $(p=0.003)$. Mortality was not observed in the patients operated on in the first 12 hours from the onset of symptoms, whereas those who were operated on at 12-24 hours and $>24$ hours had a significantly higher mortality rate $(\mathrm{p}=0.001)$. When preoperative laboratory values were analyzed, serum creatine $(\mathrm{p}<0.001)$ and serum amylase levels $(\mathrm{p}=0.014)$ and the neutrophil to lymphocyte ratio (NLR) ( $\mathrm{p}=0.017)$ were significantly higher in the non-survivors, while $\mathrm{WBC}$ values were similar in both groups $(\mathrm{p}=0.452)$.

The comparisons of operative and postoperative findings between the groups of survivors and nonsurvivors are summarized in Table 2 . The mortality rate was significantly higher in patients with a perforation diameter of $\geq 10 \mathrm{~mm}$ ( $\mathrm{p}=0.019$ ), and there was no difference in mortality rates between gastric and duodenal perforations ( $\mathrm{p}=0.722$ ). The length of hospital stay was similar in both groups ( $\mathrm{p}=0.061)$, and the length of stay in intensive care unit (ICU) was significantly higher in the group of non-survivors ( $\mathrm{p}=0.001)$.

In the univariate analysis, age $>65$ years (OR:30.37; $95 \%$ CI: 6.01 153.43; $\mathrm{p}=0.001$ ), gender (male) (OR:3.65; 95\% CI: 1.02 13.03; $\mathrm{p}=0.050$ ), $\geq$ III ASA score (OR:67.50;95\% CI: 8.08 563.26; $\mathrm{p}=0.001$ ), $\geq 1$ comorbid disease (OR: 1.37; 95\% CI: $1.14 \sim 1.66 ; \mathrm{p}=0.001),>24$ hours symptom to surgery interval (OR:4.33; 95\% CI: 1.20 15.58; $\mathrm{p}=0.031$ ) and $\geq 10 \mathrm{~mm}$ perforation (OR: 5.20 ; $95 \% \mathrm{CI}$ : $1.31 \sim 20.65 ; \mathrm{p}=0.019)$ were found to be risk factors affecting mortality. In the multivariate analysis, age $>65$ years (OR: 28.66; 95\% CI: 5.19 158.23; $\mathrm{p}=0.001$ ), $\geq$ III ASA score (OR: 0.23; 95\% CI: 0.10 0.52; $\mathrm{p}=0.001$ ); $\geq 1$ comorbid disease (OR: 15.63; 95\% CI: 1.47 165.77; $\mathrm{p}=0.022)$ and $>24$ hours symptom to surgery interval (OR: 5.45; 95\% CI:1.18 25.05; $\mathrm{p}=0.029$ ) were found to be independent predictors of postoperative mortality (Table 3). 


\begin{tabular}{|c|c|c|c|c|}
\hline \multirow{2}{*}{ Variables } & \multirow{2}{*}{ Total $(n=135)$} & \multicolumn{2}{|c|}{ Patients } & \multirow{2}{*}{$p$ value } \\
\hline & & Survivors $(\mathrm{n}=124)$ & Non-survivors $(n=11)$ & \\
\hline Age & $49.41 \pm 19.09$ & $46.74 \pm 17.23$ & $79.55 \pm 12.01$ & $<0.001$ \\
\hline Gender (male) & $107(79.3)$ & $101(81.5)$ & $6(54.5)$ & 0.050 \\
\hline ASA score & & & & $<0.001$ \\
\hline I & $74(54.8)$ & $74(59.7)$ & $0(0)$ & \\
\hline II & $35(25.9)$ & $34(27.4)$ & $1(9.1)$ & \\
\hline III & $23(17)$ & $14(11.3)$ & $9(81.8)$ & \\
\hline IV & $3(2.2)$ & $2(1.6)$ & $1(9.1)$ & \\
\hline \multicolumn{5}{|l|}{ Comorbid disease } \\
\hline Cardiovasculary disease & $24(17.8)$ & $15(12.1)$ & $9(81.8)$ & $<0.001$ \\
\hline Pulmonary disease & $6(4.4)$ & $2(1.6)$ & $4(36.4)$ & $<0.001$ \\
\hline Diabetes mellitus & $20(14.8)$ & $13(10.5)$ & $7(63.6)$ & $<0.001$ \\
\hline Chronic renal failure & $5(3.7)$ & $3(2.4)$ & $2(18.2)$ & 0.0530 \\
\hline Adrenal insufficiency & $1(0.7)$ & $1(0.8)$ & $0(0)$ & 1.000 \\
\hline Neurological disease & $2(1.5)$ & $1(0.8)$ & $1(9.1)$ & 0.157 \\
\hline Substance abuse & $1(0.7)$ & $1(0.8)$ & $0(0)$ & 1.000 \\
\hline Season of operation & & & & 0.003 \\
\hline Winter & $36(26.7)$ & $28(22.6)$ & $8(72.7)$ & \\
\hline Spring & $30(22.2)$ & $30(24.2)$ & $0(0)$ & \\
\hline Summer & $39(28.9)$ & $38(30.6)$ & $1(9.2)$ & \\
\hline Autumn & $30(22.2)$ & $28(22.6)$ & $2(18.2)$ & \\
\hline \multicolumn{2}{|c|}{ Symtom to surgery interval (hours) } & & & 0.001 \\
\hline$<12$ & $63(46.7)$ & $63(50.8)$ & $0(0)$ & \\
\hline $12-24$ & $47(34.8)$ & $41(33.1)$ & $6(54.5)$ & \\
\hline$>24$ & $25(18.5)$ & $20(16.1)$ & $5(45.5)$ & \\
\hline WBC & $13456.52 \pm 5322.97$ & $13353.39 \pm 5117.48$ & $14619.09 \pm 7479.14$ & 0.452 \\
\hline Serum creatinine & $1.07 \pm 0.64$ & $0.98 \pm 0.52$ & $2.10 \pm 0.92$ & $<0.001$ \\
\hline Serum amylase & $80.91 \pm 68.84$ & $74.60 \pm 58.43$ & $152.00 \pm 124.387$ & 0.014 \\
\hline NLR & $9.47 \pm 10.08$ & $8.27 \pm 7.94$ & $23.01 \pm 19.14$ & 0.017 \\
\hline
\end{tabular}

\begin{tabular}{|c|c|c|c|c|}
\hline \multirow{2}{*}{ Variables } & \multirow{2}{*}{ Total $(n=135)$} & \multicolumn{2}{|c|}{ Patients } & \multirow{2}{*}{$P$ value } \\
\hline & & Survivors $(\mathrm{n}=124)$ & Non-survivors $(n=11)$ & \\
\hline Site of perforation & & & & 0.722 \\
\hline Gastric & $103(76.3)$ & $95(76.6)$ & $8(72.7)$ & \\
\hline Duodenal & $32(23.7)$ & $29(23.4)$ & $3(27.3)$ & \\
\hline Size of perforation (mm) & & & & 0.019 \\
\hline$<10$ & $85(63)$ & $82(66.1)$ & $3(27.3)$ & \\
\hline$>10$ & $50(37)$ & $42(33.9)$ & $8(72.7)$ & \\
\hline \multicolumn{5}{|c|}{ Postoperative complications } \\
\hline Leakage & $1(0.7)$ & $0(0)$ & $1(9.1)$ & - \\
\hline SSI & $10(7.4)$ & $10(8.1)$ & $0(0)$ & - \\
\hline Intraabdominal abcess & $1(0.7)$ & $1(0.8)$ & $0(0)$ & - \\
\hline Insicional hernia & $1(0.7)$ & $1(0.8)$ & $0(0)$ & - \\
\hline Pneumonia & $3(2.2)$ & $2(1.6)$ & $1(9.1)$ & 0.227 \\
\hline Hospital stay (day) & $7.44 \pm 8.28$ & $6.90 \pm 3.61$ & $13.64 \pm 26.70$ & 0.061 \\
\hline Icu stay (day) & $1.25 \pm 7.98$ & $0.41 \pm 1.66$ & $10.73 \pm 26.67$ & $<0.001$ \\
\hline
\end{tabular}

Table 3. Univariate and multivariate analysis of risk factors affecting postoperative mortality

\begin{tabular}{|c|c|c|c|c|c|c|}
\hline \multirow{2}{*}{ Variables } & \multicolumn{3}{|c|}{ Univariate analysis } & \multicolumn{3}{|c|}{ Multivariate analysis } \\
\hline & OR & $95 \% \mathrm{CI}$ & P value & Adjusted OR & $95 \% \mathrm{CI}$ & P value \\
\hline Age $(>65)$ & 30.37 & $6.01 \sim 153.43$ & $<0.001$ & 28.66 & $5.19 \sim 158.23$ & $<0.001$ \\
\hline Gender (male) & 3.65 & $1.02 \sim 13.03$ & 0.050 & - & - & - \\
\hline ASA score ( $\geq \mathrm{III})$ & 67.50 & $8.08 \sim 563.26$ & $<0.001$ & 0.23 & $0.10 \sim 0.52$ & $<0.001$ \\
\hline Comorbid disease $(\geq 1)$ & 1.37 & $1.14 \sim 1.66$ & $0.001>$ & 15.63 & $1.47 \sim 165.77$ & 0.022 \\
\hline Symptom to surgery interval ( $>24$ hours) & 4.33 & $1.20 \sim 15.58$ & 0.031 & 5.45 & $1.18 \sim 25.05$ & 0.029 \\
\hline Size of perforation $(\geq 10 \mathrm{~mm})$ & 5.20 & $1.31 \sim 20.65$ & 0.019 & - & - & - \\
\hline
\end{tabular}




\section{DISCUSSION}

Peptic ulcer disease is one of the most common gastrointestinal diseases. The frequency of PUD is estimated to be 1500-3000/100,000. An individual's lifetime chance of developing PUD is approximately $5 \%$ (9). The use of proton pump inhibitors for the treatment of peptic ulcer disease has led to a reduction in elective ulcer surgery (10). However, despite these developments, the rate of perforation in peptic ulcer disease is up to $7 \%$ per year (11). PUP is one of the high-risk surgical acute abdominal conditions that can cause general or localized peritonitis, sepsis and death. Morbidity (50\%) and morbidity (4-30\%) rates have been reported to be high in many studies $(12,13)$. In a study by Aydin and Pehlivan, the mortality rate was found to be $17.4 \%$ (14). In the current study, this rate was found to be $8.1 \%$. Peptic ulcer perforation is generally seen between the ages of 40 and 50 years, and the mean age of the current study patients was 49.4 years, similar to the literature (5). Arveen et al. (15) reported the male-female ratio of 10.3:1.0, and this rate has been shown to be similar, particularly in studies in eastern countries. However, different studies have shown a marked increase in the number of female patients $(5,15,16)$. In the current study of 135 patients, there were 107 (79.3\%) males and 28 (20.7\%) females, with a significantly higher number of male patients. Testini et al., reported that patients over 65 years of age had a significantly higher mortality rate than younger patients because of the more frequent presence of comorbid diseases (17). In a study conducted by Kocer et al. (5), the mortality rate was $1.4 \%$ in patients aged $<65$ years and $37.3 \%$ in those $>65$ years. In accordance with the literature, the current study results showed that the mortality rate of patients aged $>65$ years was significantly high. Comorbid diseases such as cardiovascular diseases, lung diseases and diabetes mellitus were found to be significantly more frequent in the group with mortality. The mean length of hospital stay was reported to be 10.9 days by Arveen et al. (15), and mean 11.6 days (maximum 46 days) by Sivaram et al. (13) and there was observed to be a correlation compatible with mortality when the hospital stay exceeded two weeks. In the current study, there was no difference between the groups in respect of duration of hospitalization but the length of stay in the intensive care unit was significantly longer in the group that developed mortality. In a study by Kim et al. (18), female gender was determined to be a factor related with mortality. In the current series, the mortality rate in females was found to be significantly higher. In a study by Taș et al. (19), the perforation location was determined to be pre-pyloric in $68.2 \%$ and in the duodenum in $31.8 \%$ and perforation diameter $>0.5 \mathrm{~cm}$ was associated with mortality. In the study by Sivaram et al. (13), it was reported that perforation diameter $>1$ $\mathrm{cm}$ increased mortality. In the current study, perforation location was determined as $76.3 \%$ in the stomach and $23.7 \%$ in the duodenum, and location was not associated with mortality. Perforation diameter $>1 \mathrm{~cm}$ was found to be a factor affecting mortality. It has been reported that mortality rates are higher in patients undergoing PUP surgery who have high ASA scores $(20,21)$. In the univariate analysis of a study by Ünver et al. (22), the ASA score was determined to be an important risk factor related to mortality. In the current study, patients with an ASA score of $\geq 3$ had a higher risk of mortality.

Various inflammatory-based scoring systems have been proposed to predict the prognosis of inflammatory diseases, including platelet-lymphocyte ratio, prognostic nutritional index, and neutrophil-lymphocyte ratio (NLR) (23). Derived from circulating neutrophil and lymphocyte counts, the NLR has attracted great attention as it can be measured non-invasively, is easily detected in peripheral blood and does not incur any additional costs (24). In a study by Aydin and Pehlivanli (14), it was suggested that NLR was not statistically significant in determining the mortality in patients operated on due to PUP, but it could be used as a biomarker to predict the decrease in the number of preoperative lymphocytes (14). In the current series, the preoperative NLR was found to be associated with postoperative mortality. Suriya et al. reported that a $\mathrm{BUN} /$ creatinine ratio of 12 times or more was associated with PUP (25). Moller et al. (26) concluded that the creatinine value is one of the factors affecting mortality in peptic ulcer perforation. Perforation time is generally considered the onset of pain, and Boey et al. found that prolonged perforation $(24 \mathrm{~h})$ is an important prognostic risk factor (27). Although Suriya et al. (25) found a similar result, Tas et al. (19) reported no correlation between admission time and increased morbidity. In the current study, it was observed that the preoperative high creatinine value and surgery within 12 hours of the onset of pain are important factors for mortality.

\section{CONCLUSION}

Despite effective resuscitation and rapid surgical intervention, PUP is still an important complication of PUD, which currently has high mortality and morbidity rates. Advanced age, male gender, the time between the onset of pain and surgery of more than 12 hours, ASA score of $\geq 3$, comorbid diseases, perforation diameter $>1 \mathrm{~cm}$, preoperative creatine, amylase and NLR are important factors affecting mortality. Understanding these preoperative and intraoperative factors and identifying patients at risk can help reduce postoperative morbidity rates. 


\section{ETHICAL DECLARATIONS}

Ethics Committee Approval: Prior to implementation, this study's protocol was approved by Ankara Training and Research Hospital Ethics Committee (Date: 01/10/2020, Decision No: 442).

Informed Consent: Because the study was designed retrospectively, no written informed consent form was obtained from patients.

\section{Referee Evaluation Process: Externally peer-reviewed.}

Conflict of Interest Statement: The authors have no conflicts of interest to declare.

Financial Disclosure: The authors declared that this study had received no financial support.

Author Contributions: All of the authors declare that they have all participated in the design, execution, and analysis of the paper and approved the final version.

\section{REFERENCES}

1. Zelickson MS, Bronder CM, Johnson BL, et al. Helicobacter pylori is not the predominant etiology for peptic ulcers requiring operation.Am Surg 2011; 77: 1054-60.

2. Thorsen K, Glomsaker TB, von Meer A, Søreide K, Søreide JA. Trends in diagnosis and surgical management of patients with perforated peptic ulcer. J Gastrointest Surg 2011; 15: 1329-35.

3. Tanrikulu Y, Tanrikulu CS, Sabuncuoglu MZ, Kokturk F, Temi V, Bicakci E. Is the neutrophil-to-lymphocyte ratio a potential diagnostic marker for peptic ulcer perforation? A retrospective cohort study. Am J Emerg Med 2016; 34: 403-6.

4. Lau JY, Sung J, Hill C, Henderson C, Howden CW, Metz DC. Systematic review of the epidemiology of complicated peptic ulcer disease: incidence, recurrence, risk factors and mortality Digestion 2011; 84: 102-13.

5. Koçer B, Sürmeli S, Solak C, et al. Factors affecting mortality and morbidity in patients with peptic ulcer perforation. J Gastroenterol Hepatol 2007; 22: 565-70.

6. Sarosi GA, Jaiswal KR, Nwariaku FE, Asolati M, Fleming JB, Anthony T. Surgical therapy of peptic ulcers in the 21st century: more common than you think. Am J Surg 2005; 190: 775-9.

7. Chalya PL, Mabula JB, Koy M, et al. Clinical profile and outcome of surgical treatment of perforated peptic ulcers in Northwestern Tanzania: A tertiary hospital experience. World J Emerg Surg 2011; 6: 31 .

8. Lohsiriwat V, Prapasrivorakul S, Lohsiriwat D. Perforated peptic ulcer: clinical presentation, surgical outcomes, and the accuracy of the Boey scoring system in predicting postoperative morbidity and mortality. World J Surg 2009; 33: 80-5.

9. Zittel TT, Jehle EC, Becker HD. Surgical management of peptic ulcer disease todayindication, technique and outcome Langenbecks Arch Surg 2000; 385: 84-96.

10. Mäkelä J, Laitinen S, Kairaluoma MI. Complications of peptic ulcer disease before and after the introduction of $\mathrm{H} 2$ receptor antagonists. Hepatogastroenterology 1992; 39: 144-8.

11. Casali JJ, Franzon O, Kruel NF, Neves BD. Epidemiological analysis and use of rapid urease test in patients with perforated peptic ulcers. Rev Col Bras Cir 2012; 39: 93-8.

12.Søreide K, Thorsen K, Harrison EM, Bingener J, Moller MH, Ohene-Yeboah M. Perforated peptic ulcer. Lancet 2015; 386: 1288-98.
13. Sivaram P, Sreekumar A. Preoperative factors influencing mortality and morbidity in peptic ulcer perforation. Eur J Trauma Emerg Surg 2018; 44: 251-7.

14. Aydın O, Pehlivanlı F. Is the Platelet to lymphocyte ratio a potential biomarker for predicting mortality in peptic ulcer perforation? Surg Infect (Larchmt) 2019; 20: 326-31.

15. Arveen S, Jagdish S, Kadambari D. Perforated peptic ulcer in South India: an institutional perspective. World J Surg 2009; 33: $1600-4$.

16. Taj MH, Mohammad D, Qureshi SA. Outcome of omentopexyas primary repair in perforated duodenal ulcer. J Coll Physicians Surg Pak 2007; 17: 731-5.

17. Testini M, Portincasa P, Piccinni G, Lissidini G, Pellegrini F, Greco L. Significant factors associated with fatal outcome in emergency open surgery for perforated peptic ulcer. World J Gastroenterol 2003; 9: 2338-40.

18. Kim J-M, Jeong S-H, Lee Y-J, et al. Analysis of risk factors for postoperative morbidity in perforated peptic ulcer. J Gastric Cancer 2012; 12: 26-35.

19. Taş I, Ülger BV, Önder A, et al. Risk factors influencing morbidity and mortality in perforated peptic ulcer disease. Ulus Cerrahi Derg 2014; 31: 20-5.

20.Kujath P, Schwandner O, Bruch HP. Morbidity and mortality of perforated peptic gastroduodenal ulcer following emergency surgery. Langenbecks Arch Surg 2002; 387: 298-302.

21. Barut I, Tarhan OR, Cerci C, Karaguzel N, Akdeniz Y, Bulbul M. Prognostic factors of peptic ulcer perforation. Saudi Med J 2005; 26: $1255-9$.

22. Unver M, Firat O, Unalp OV, et al. Prognostic factors in peptic ulcer perforations: a retrospective 14-year study. Int Surg 2015; 100: $942-8$.

23. Proctor MJ, Morrison DS, Talwar D, et al. A comparison of inflammation-based prognostic scores in patients with cancer. A Glasgow Inflammation Outcome Study. Eur J Cancer 2011; 47: 2633-41.

24.de Jager CP, van Wijk PT, Mathoera RB, de Jongh-Leuvenink J, van der Poll T, Wever PC. Lymphocytopenia and neutrophillymphocyte count ratio predict bacteremia better than conventional infection markers in an emergency care unit. Crit Care 2010; 14: R192.

25. Suriya C, Kasatpibal N, Kunaviktikul W, Kayee T. Diagnostic indicators for peptic ulcer perforation at a tertiary care hospital in Thailand. Clin Exp Gastroenterol 2011; 4: 283-9.

26. Møller MH, Engebjerg MC, Adamsen S, Bendix J, Thomsen RW. The Peptic ulcer perforation (PULP) score: a predictor of mortality following peptic ulcer perforation. A cohort study. Acta Anaesthesiol Scand 2012; 56: 655-62.

27. Boey J, Choi SK, Poon A, Alagaratnam TT. Risk stratification in perforated duodenal ulcers. A prospective validation of predictive factors. Ann Surg 1987; 205: 22-6. 